\section{Cureus}

Received 05/01/2016

Review began 05/03/2016

Review ended 05/07/2016

Published 06/04/2016

\section{(c) Copyright 2016}

Ajayi et al. This is an open access article distributed under the terms of the Creative Commons Attribution License CC-BY 3.0., which permits unrestricted use, distribution, and reproduction in any medium, provided the original author and source are credited.

\title{
C2 Pedicle Screw Placement: A Novel Teaching Aid
}

\author{
Olaide Ajayi ${ }^{1}$, Marc Moisi ${ }^{2}$, Jens Chapman ${ }^{3}$, Rod J. Oskouian ${ }^{4}$, R. Shane Tubbs ${ }^{5}$ \\ 1. Department of Neurosurgery, Loma Linda University Medical Center 2. Neurosurgery, Seattle Science \\ Foundation, Seattle, Select Country 3. Orthopedics Spine Surgery, Swedish Neuroscience Institute, \\ Seattle, USA 4. Neurosurgery, Swedish Neuroscience Institute, Seattle, USA 5. Neurosurgery, Seattle \\ Science Foundation, Seattle, USA
}

$\square$ Corresponding author: Olaide Ajayi, ooajayi1@yahoo.com

Disclosures can be found in Additional Information at the end of the article

\section{Abstract}

The C2 pedicle screw is more biomechanically stable and provides patients with increased postoperative range of motion in comparison to other methods of $\mathrm{C} 2$ fixation. However, as a result of the proximity of the $\mathrm{C} 2$ pedicle to the transverse foramen, there is a considerable risk of intraoperative morbidity due to vertebral artery injury laterally or vertebral canal breach medially. Other than the use of cadavers for the demonstration and practice of C2 pedicle screw placement, there are currently few other readily available teaching aids for the training of residents and fellows. Herein, we describe a simple and cost effective modality for the demonstration, evaluation, and practice of C2 pedicle screw placement in a laboratory setting.

Categories: Neurosurgery

Keywords: c2 pedicle screw, teaching aid, technique

\section{Introduction}

Atlantoaxial instability may occur as a result of trauma, tumors, congenital malformations, or inflammatory conditions of the upper cervical spine [1-2]. Fixation techniques for the treatment of atlantoaxial instability have evolved from spinous process wiring techniques first described by Mixter and Osgood in 1910 [3-4], to laminar wiring described by Gallie in 1939 [3, 5] and C12 laminar wiring described by Brooks and Jenkins in 1978. Dickman and Sonntag further modified the posterior wiring technique in $1991[3,6]$.

Posterior C1-C2 transarticular screws and C1-lateral mass screws with C2 pars screws are some of the more recently developed methods of C1-C2 fixation. The C2 pedicle screw was first described by Goel, et al. in the 1980s as part of a plate and screw construct that was utilized for posterior C1-2 fixation [3, 7-8]. This technique has been further modified, with a variety of poly-axial screws and top-loading rods now widely available for C2 pedicle fixation.

The choice of any of these methods of fixation over another are influenced by anatomic constraints or variations, surgeon's preference and/or experience [1,9] as well as comparative knowledge of the strengths and limitations of each construct.

\section{Background}

The C2 pedicle screw technique has numerous advantages over other methods of C2 fixation such as the C1-2 transarticular screw technique, the C2 lateral mass screw as well as the 


\section{Cureus}

posterior wiring techniques. These advantages include increased range of motion postoperatively as well as stronger biomechanical stability. Based on a biomechanical study by Lehman, et al., C2 pedicle screws generated a greater insertional torque and pull-out strength in comparison to lateral mass, pars, and laminar screws. [10]

C2 pedicle screw placement is technically demanding and the precise and exact threedimensional understanding of the anatomy of the region and vertebral artery is mandatory [3]. Apart from utilizing cadavers to demonstrate the placement of C2 pedicle screws and the avoidance of complications (such as vertebral artery injury or spinal cord injury due to medial breach of the pedicle screw into the vertebral canal) during the procedure, there are currently few teaching aids for the training of residents and fellows.

Herein, we describe an easily applicable teaching aid that utilizes dried human C2 vertebrae to demonstrate the procedure while highlighting the avoidance of complications.

\section{Technical Report}

The $\mathrm{C} 2$ pedicle is the portion of the $\mathrm{C} 2$ vertebra anterior to the pars, connecting the dorsal elements with the vertebral body. The entry point for the $\mathrm{C} 2$ pedicle screw is usually $5 \mathrm{~mm}$ rostral and $1 \mathrm{~mm}$ medial to the inferomedial aspect of the inferior articulating surface of $\mathrm{C} 2$. The screw is placed with 15-25 degrees of medial angulation with the thick medial wall of the C2 pedicle helping to redirect the screw if necessary, to prevent medial wall breakout and entry into the spinal canal. [3]

\section{Discussion}

\section{Methods}

Utilizing dry vertebrae, the superior articulating surface of C2 is cut off at its lateral point of attachment with a high speed drilling disc (Dremel rotary tool, Robert Bosch Tool Corporation, IL, USA), exposing the $\mathrm{C} 2$ pedicle and the entirety of the $\mathrm{C} 2$ transverse foramen as shown in Figure 1.

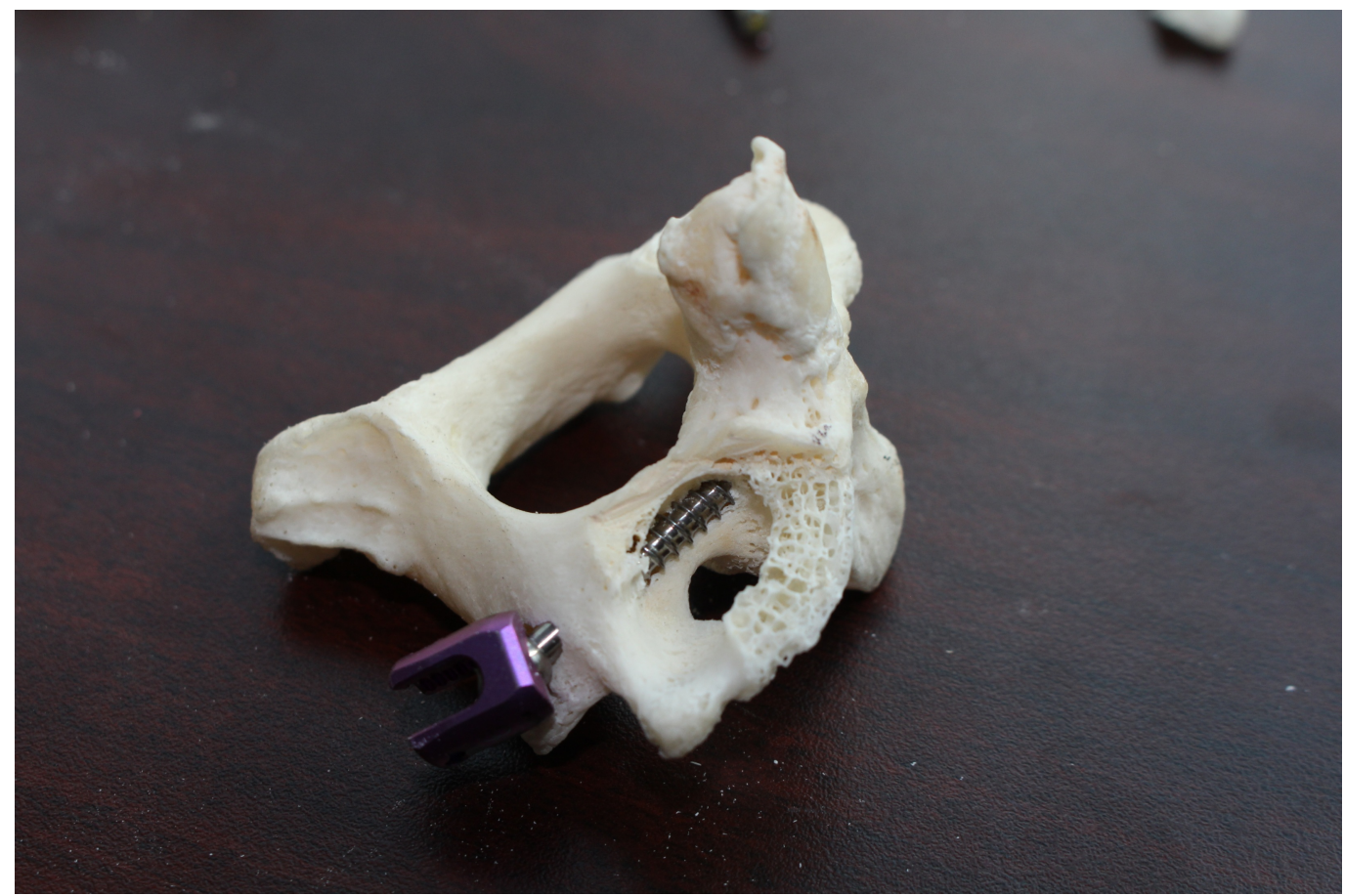




\section{Cureus}

FIGURE 1: The superior articulating surface of $\mathrm{C} 2$ has been cut off, exposing the trajectory of the $\mathrm{C} 2$ pedicle screw and the proximity of the pedicle screw to the transverse foramen.

This provides the trainee with a better appreciation for the feel of the pedicle screw as it traverses cortical and cancellous bone, while having clear visual feedback of the position of the pedicle screw relative to surrounding structures in real time. The cut off superior articulating surface of C2 can be hinged off the odontoid process with a small metal spring as shown in Figure 2 .

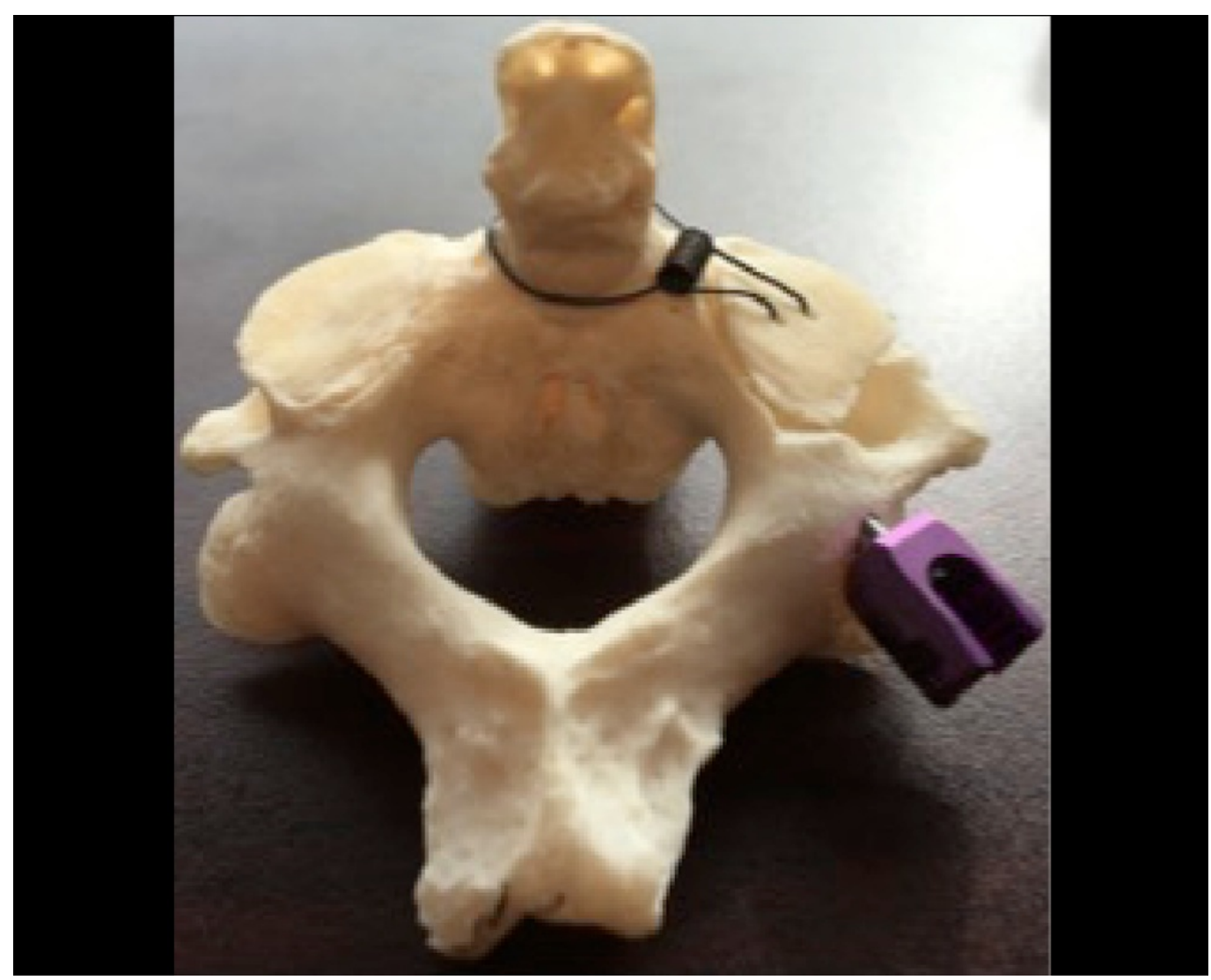

FIGURE 2: The superior articulating surface of $\mathrm{C} 2$ is hinged off the dens and flapped back into place, allowing for free-hand placement of the $\mathrm{C} 2$ pedicle screw.

This allows for practice placement of the $\mathrm{C} 2$ pedicle screw by the trainee based on the landmarks and trajectory described above, as shown in Figure 3. 


\section{Cureus}

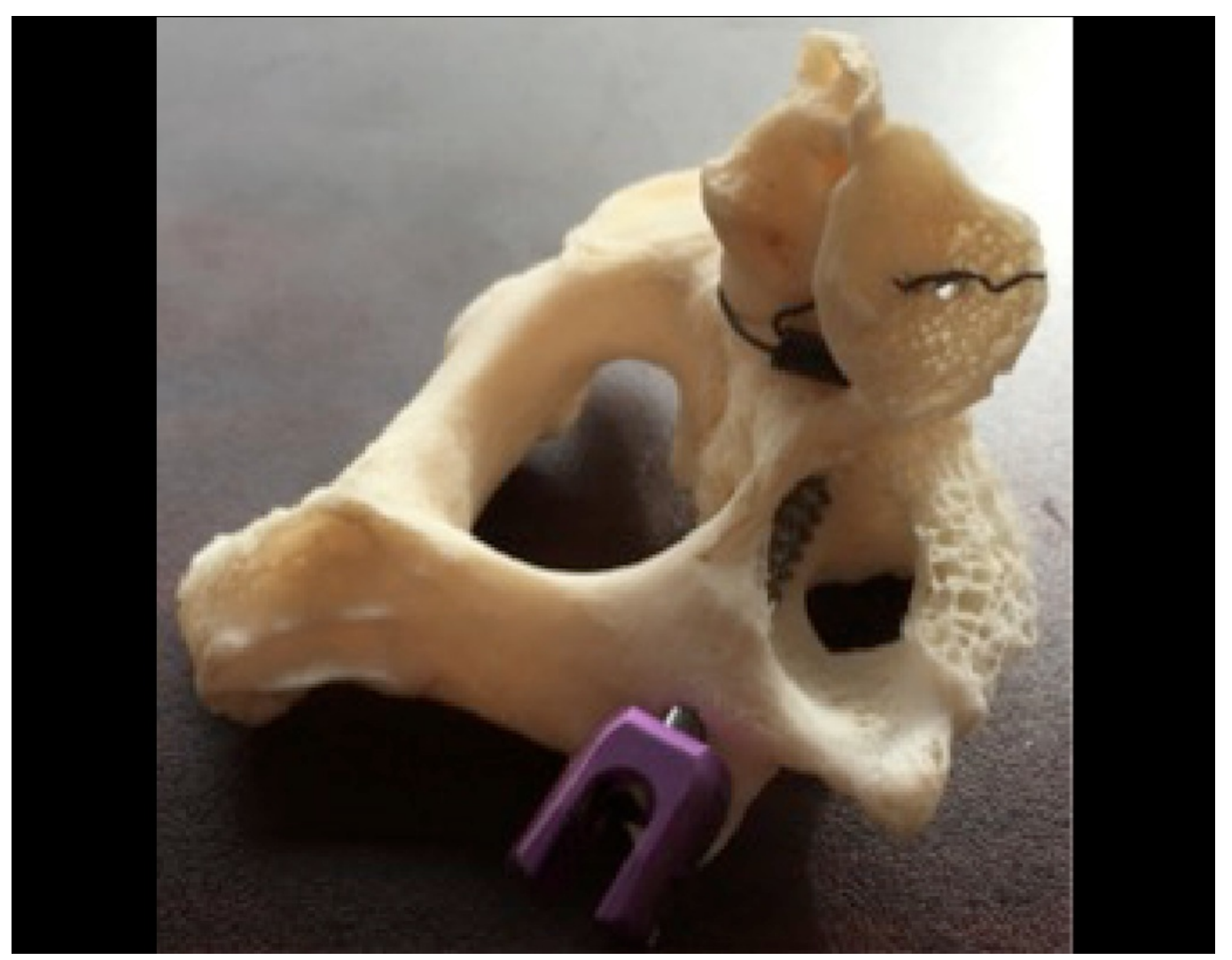

FIGURE 3: The superior articulating surface of C2 is lifted up to evaluate the trajectory of the pedicle screw and its proximity to the transverse foramen.

The placement of the screw can then once again be evaluated by lifting the hinged superior articular process and assessing the proximity of the pedicle screw to surrounding structures such as the vertebral artery, which is delineated with a red plastic tube in Figure 4. 


\section{Cureus}

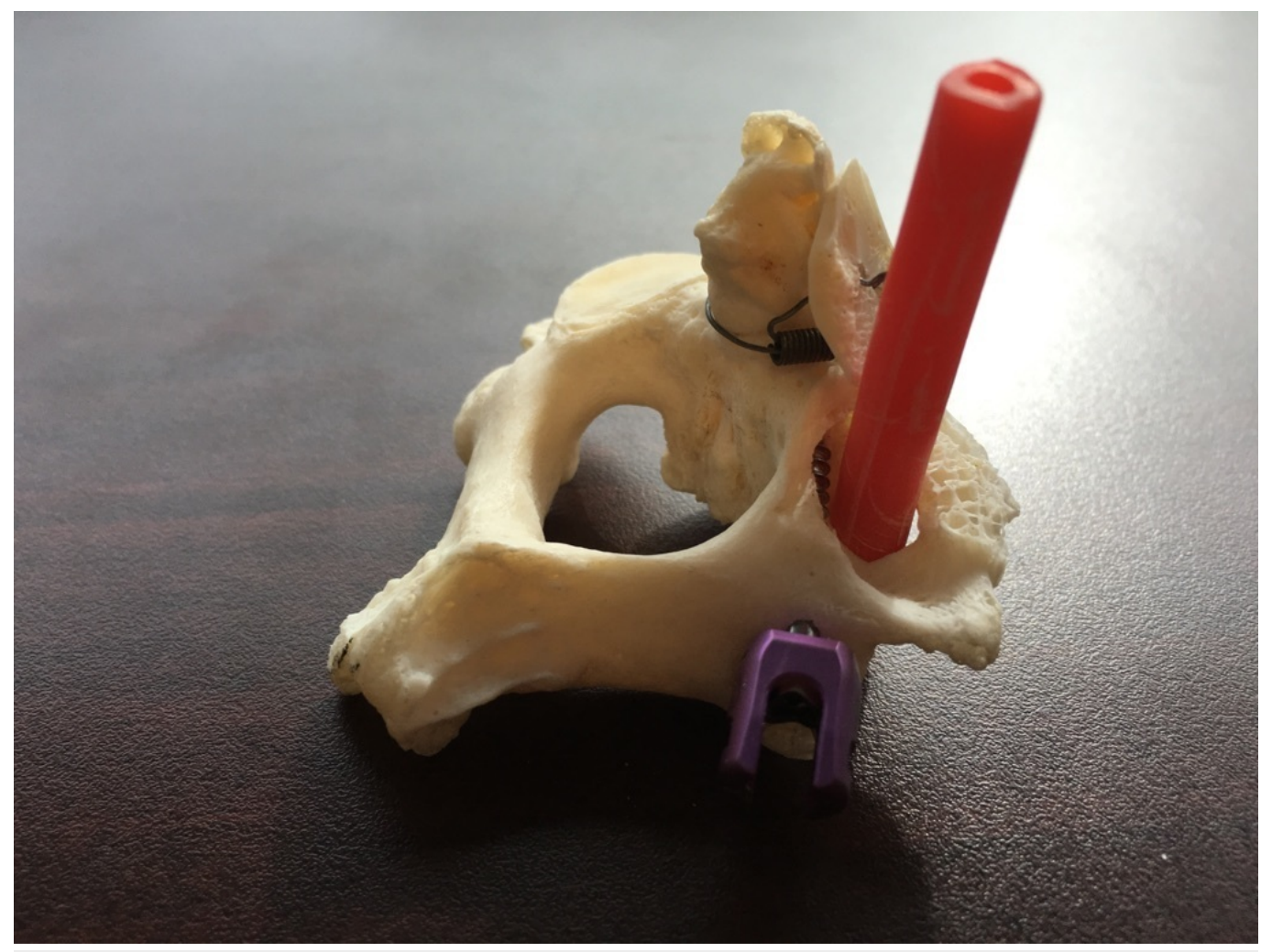

FIGURE 4: A red tube representing the vertebral artery traversing the $\mathrm{C} 2$ transverse foramen shows the proximity of the C2 pedicle to the vertebral artery.

This can be repeated as often as necessary until the trainee is comfortable with the technique.

\section{Conclusions}

This cheap and simple teaching aid provides a much needed avenue for preparing trainees for real-life C2 pedicle screw placement while avoiding the associated risks of intraoperative training or the usually prohibitive cost of providing cadavers for training residents and fellows. It can also easily be applied to other technically challenging spinal instrumentation procedures such as $\mathrm{C} 1$ lateral mass and thoracic pedicle screw placement.

\section{Additional Information}

\section{Disclosures}

Human subjects: All authors have confirmed that this study did not involve human participants or tissue. Animal subjects: All authors have confirmed that this study did not involve animal subjects or tissue. Conflicts of interest: In compliance with the ICMJE uniform disclosure form, all authors declare the following: Payment/services info: All authors have declared that no financial support was received from any organization for the submitted work. Financial relationships: All authors have declared that they have no financial relationships at present or within the previous three years with any organizations that might have an interest in the submitted work. Other relationships: All authors have declared that there are no other relationships or activities that could appear to have influenced the submitted work. 


\section{References}

1. Savage JW, Limthongkul W, Park HS, Zhang L, Karaikovic EE: A comparison of biomechanical stability and pullout strength of two C1-C2 fixation constructs. Spine J. 2011, 11:654-658.

10.1016/j.spinee.2011.04.022

2. Claybrooks R, Kayanja M, Milks R, Benzel E: Atlantoaxial fusion: a biomechanical analysis of two C1-C2 fusion techniques. Spine J. 2007, 7:682-688.

3. Mummaneni PV, Haid RW: Atlantoaxial fixation: overview of all techniques . Neurol India. 2005, 53:408-415.

4. Mixter SJ, Osgood RB: Traumatic lesions of the atlas and axis. Ann Surg. 1910, 51:193-207.

5. Gallie WE: Fractures and dislocations of the cervical spine. Am J Surg. 1939, 46:495-499. 10.1016/S0002-9610(39)90309-0

6. Dickman CA, Sonntag VK, Papadopoulos SM, Hadley MN: The interspinous method of posterior atlantoaxial arthrodesis. J Neurosurg. 1991, 74:190-198.

7. Goel A, Laheri V: Plate and screw fixation for atlanto-axial subluxation. Acta Neurochir (Wien). 1994, 129:47-53.

8. Goel A, Desai K, Muzumdar DP: Atlantoaxial fixation using plate and screw method: a report of 160 treated patients. Neurosurgery. 2002, 51:1351-1356.

9. Abou Madawi A, Solanki G, Casey AT, Crockard HA: Variation of the groove in the axis vertebra for the vertebral artery. Implications for instrumentation. J Bone Joint Surg Br. 1997, 79:820-823.

10. Lehman RA, Dmitriev AE, Helgeson MD, Sasso RC, Kuklo TR, Riew KD: Salvage of C2 pedicle and pars screws using the intralaminar technique: a biomechanical analysis. Spine. 2008, 33:960-965. 10.1097/BRS.0b013e31816c915b 